\title{
Glomerular Filtration Rate as a Prognostic Factor for Long-Term Mortality after Acute Pulmonary Embolism
}

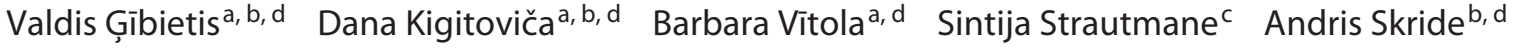 \\ ${ }^{a}$ Faculty of Continuing Education, Riga Stradins University, Riga, Latvia; ${ }^{b}$ Department of Internal Medicine, Riga Stradins \\ University, Riga, Latvia; 'Faculty of Medicine, Riga Stradins University, Riga, Latvia; d Pauls Stradins Clinical University Hospital, \\ Riga, Latvia
}

\section{Significance of the Study}

- This original prospective cohort study explores the importance of renal function not only as a shortterm but also as a long-term prognostic marker for patients with acute PE. The results of this study suggest the usefulness of estimated glomerular filtration rate and creatinine clearance as an additional tool for risk stratification of these patients in clinical practice.

\section{Keywords}

Glomerular filtration rate - Mortality · Pulmonary embolism . Renal insufficiency · Venous thromboembolism

\begin{abstract}
Background: In-hospital mortality for patients presenting with acute pulmonary embolism (PE) has been reported to be up to 7 times higher for patients with decreased estimated glomerular filtration rate (eGFR). However, few studies have assessed its effect on long-term mortality. Objective: To determine the impact of eGFR and creatinine clearance $(\mathrm{CrCl})$ on long-term all-cause mortality following acute $\mathrm{PE}$ in association with other routine laboratory analyses and comorbidities. Patients/Methods: The prospective study enrolled 141 consecutive patients presenting with objectively confirmed acute PE. Demographic, clinical data, comorbidities, and laboratory values were recorded. $\mathrm{CrCl}$ and GFR were estimated using the Cockcroft-Gault, MDRD, and chronic kidney disease (CKD)-EPI equations. Patients were followed up at 90 days and 1 year after the event. Results: In univari-
\end{abstract}

ate analyses, age, active cancer, $\mathrm{PE}$ severity index (PESI), $\mathrm{CrCl}$ and eGFR, D-dimer value, and high-density lipoprotein level were found to be significantly associated with mortality in 90 days and 1 year. Additionally, body mass index was significant in the 1-year follow-up. $\mathrm{CrCl}$ by Cockcroft-Gault (90-day: area under the curve [AUC] 0.763; 1-year: AUC 0.718) demonstrated higher discriminatory power for predicting mortality than eGFR by the MDRD (AUC 0.686; AUC 0.609) and CKD-EPI (AUC 0.697; AUC 0.630) equations. In multivariate analyses, active cancer, $\mathrm{CrCl}$ by Cockcroft-Gault (90-day: hazard ratio [HR] 0.948, 95\% Cl 0.919-0.979; 1-year: HR 0.967, 95\% Cl 0.943-0.991), eGFR by CKD-EPI (90-day: HR 0.948, 95\% Cl 0.915-0.983; 1-year: HR 0.971, 95\% Cl 0.945-0.998) were found to be independent predictors of mortality. eGFR by MDRD, D-dimer, and PESI value were significant prognostic factors for 90-day mortality. Conclusion: Decreased renal function is a prognostic factor for increased all-cause mortality 90 days and 1 year after acute PE.

C 2019 The Author(s)

Published by S. Karger AG, Basel

\begin{tabular}{|c|c|c|}
\hline KARGER & $\begin{array}{l}\text { (c) } 2019 \text { The Author(s) } \\
\text { Published by S. Karger AG, Basel }\end{array}$ & $\begin{array}{l}\text { Karger } \\
\text { Open access }\end{array}$ \\
\hline $\begin{array}{l}\text { E-Mail k } \\
\text { www.ka }\end{array}$ & $\begin{array}{l}\text { This is an Open Access article licensed } \\
\text { Attribution-NonCommercial- } 4.0 \text { Inte } \\
\text { (http://www.karger.com/Services/Ope } \\
\text { the online version of the article only. } L \\
\text { mercial purposes requires written per }\end{array}$ & $\begin{array}{l}\text { the Creative Commons } \\
\text { al License (CC BY-NC) } \\
\text { sLicense), applicable to } \\
\text { d distribution for com- }\end{array}$ \\
\hline
\end{tabular}

Valdis Gībietis

Faculty of Continuing Education, Riga Stradins University

16 Dzirciema Street

LV-1007 Riga (Latvia)

E-Mail valdisgib@gmail.com 


\section{Introduction}

Venous thromboembolism (VTE) is the third most common cause of death from cardiovascular disease after acute myocardial infarction and stroke $[1,2]$ with an overall annual incidence of $104-183$ per 100,000 person years in European ancestry [3]. Renal dysfunction is an important risk factor for cardiovascular disease and is associated with increased mortality and morbidity [4]. The high incidence of VTE in end-stage renal disease, nephrotic syndrome, or stages 3 and 4 chronic kidney disease (CKD) is well known [5-8]. Furthermore, mild to moderate CKD is associated with a procoagulant profile [9].

The prognostic importance of CKD and decreased estimated glomerular filtration rate (eGFR) for patients with acute pulmonary embolism (PE) has been studied; however, there is no definitive data with regard to the impact of CKD on in-hospital mortality for PE [10]. Although various studies show the impact of renal dysfunction on the short-term prognosis in these patients [1015], few studies have assessed its effect on long-term mortality [15], hence, the importance of decreased renal function as a prognostic marker is yet to be fully determined. Acute PE itself can contribute to acute kidney injury, which predicts higher all-cause mortality in 30 days [16] in addition to previously observed kidney dysfunction and worse short-term outcomes in case of a PE event $[13,14]$.

The aim of this study was to determine the impact of eGFR and $\mathrm{CrCl}$ on long-term all-cause mortality following acute $\mathrm{PE}$ in association with other routine laboratory analyses and comorbidities.

\section{Materials and Methods}

\section{Study Population}

Patients were eligible for our study if the diagnosis of acute PE was confirmed by computed tomography pulmonary angiography (CTPA). All radiographic images were analyzed by experienced radiologists. All included patients had a recent onset of PE symptoms during the previous 10 days. All patients provided written or oral consent for participation in the registry in accordance with local hospital ethics committee requirements. We made all efforts to enroll consecutive patients admitted to the hospital. Data were recorded in a computer-based registry.

\section{Study Design}

We conducted a prospective cohort study and retrospectively analyzed data in a single hospital. The following parameters were recorded: baseline characteristics of patients; clinical status, including any coexisting or underlying conditions such as chronic heart or lung disease; risk factors for PE; laboratory findings in- cluding hemoglobin, leukocytes, platelet count, D-dimers, creatinine, troponin-I, brain natriuretic peptide (BNP), total cholesterol, high-density lipoprotein (HDL), low-density lipoprotein, and triglycerides. For all patients, clinical parameters, hemoglobin, leukocytes, platelet count, D-dimers, creatinine, and troponin-I were taken upon admission at the hospital or were recorded from the first test available after the onset of symptoms in cases where the index event took place in the hospital. Creatinine was measured before CTPA was performed. Initial serum creatinine levels were compared to the last repeated measurement before hospital discharge. Using this information and previous records from patient history, patients were classified as having transient, maintained (chronic), or no renal dysfunction. Renal dysfunction was defined as $\mathrm{CrCl}$ by Cockcroft-Gault below $60 \mathrm{~mL} / \mathrm{min}$. The definitions of transient, maintained (chronic), and no renal dysfunction were as follows: no renal dysfunction - stable estimated $\mathrm{CrCl}$ of no less than $60 \mathrm{~mL} / \mathrm{min}$; transient - $\mathrm{CrCl}$ below $60 \mathrm{~mL} / \mathrm{min}$ upon admission with return to a value above $60 \mathrm{~mL} / \mathrm{min}$ during the hospital stay or subsequent measurements in the following 3 months; maintained (chronic) - $\mathrm{CrCl}$ persistently below $60 \mathrm{~mL} / \mathrm{min}$ during the hospital stay and subsequent measurements and previously known CKD in stages 3-5. Active cancer was categorized as newly diagnosed cancer, metastatic cancer, or cancer that is being treated. PE severity index (PESI) was calculated for all patients. Renal function was estimated using $\mathrm{CrCl}$ by Cockcroft-Gault and eGFR by MDRD and Chronic Kidney Disease Epidemiology Collaboration (CKD-EPI) formulas. All patients had a follow-up at 90 days and 1 year.

\section{Statistical Analysis}

Data were expressed as absolute numbers and percentage, mean and SD, or median and interquartile range where appropriate. SPSS, version 23.0, was used for all analyses. Univariate analyses were conducted using independent samples $t$ test, Mann-Whitney $U$ test, $\chi^{2}$-test, and Fisher's exact test where appropriate. To assess the independent effect on mortality of statistically significant variables in univariate analysis, multivariate Cox regression analysis was performed. Variables were tested for collinearity and proportionality assumption. Receiver-operating characteristic (ROC) was used to determine the prognostic value for mortality of different GFR/CrCl estimation formulas. A $p$ value $<0.05$ was considered statistically significant.

\section{Results}

The study population consisted of 141 patients of whom 87 (61.7\% [95\% CI 53.1-69.8]) were female. Mean age was 66 (SD 16) years (range 23-92). All-cause mortality rate within 90 days and 1 year was $13.5 \%$ (95\% CI 8.3$20.2 ; n=19)$ and $17.7 \%(95 \%$ CI $11.8-25.1 ; n=25)$, respectively. Causes of death were classified as cardiovascular $(n=8)$, directly attributable to malignancy $(n=9)$, multiorgan dysfunction $(n=5)$, and other $(n=3)$. Demographic, clinical, and laboratory characteristics of patients according to 90-day and 1-year outcomes are presented in Tables 1 and 2. 
Table 1. Patient characteristics according to mortality within 90 days

\begin{tabular}{|c|c|c|c|c|}
\hline & All patients & 90-day nonsurvivors & 90-day survivors & $p$ value \\
\hline Patients, $n(\%)$ & $141(100)$ & $19(13.5)$ & $122(86.5)$ & - \\
\hline Age, years, mean \pm SD & $66 \pm 16$ & $73 \pm 13$ & $65 \pm 16$ & $0.030^{*}$ \\
\hline Gender, female, $n(\%)$ & $87(61.7)$ & $12(63.2)$ & $75(61.5)$ & 0.888 \\
\hline $\mathrm{BMI}, \mathrm{kg} / \mathrm{m}^{2}$, mean $\pm \mathrm{SD}$ & $29.5 \pm 5.7$ & $27.3 \pm 5.2$ & $29.8 \pm 5.7$ & 0.058 \\
\hline Chronic heart failure & $62(44.0)$ & $9(47.4)$ & $53(43.4)$ & 0.748 \\
\hline Chronic lung disease & $17(12.1)$ & $1(5.3)$ & $16(13.1)$ & 0.469 \\
\hline Diabetes & $22(15.6)$ & $5(26.3)$ & $17(13.9)$ & 0.179 \\
\hline Atrial fibrillation & $28(19.9)$ & $5(26.3)$ & $23(18.9)$ & 0.536 \\
\hline Myocardial infarction & $26(18.4)$ & $5(26.3)$ & $21(17.2)$ & 0.347 \\
\hline Cerebral ischemia & $14(9.9)$ & $2(10.5)$ & $12(9.8)$ & 1.000 \\
\hline Systolic blood pressure, $\mathrm{mm} \mathrm{Hg}$ & $130(110-140)$ & $130(110-145)$ & $130(110-140)$ & 0.889 \\
\hline Respiratory rate,$\times / \min$ & $18(16-22)$ & $18(15-21)$ & $18(16-22)$ & 0.764 \\
\hline Heart rate, bpm & $90(78-104)$ & $80(68-90)$ & $90(80-104)$ & 0.073 \\
\hline \multicolumn{5}{|l|}{ Scales } \\
\hline PESI, median (IQR) & $89(74-107)$ & $119(91-138)$ & $88(71-102)$ & $0.002^{*}$ \\
\hline \multicolumn{5}{|l|}{ Risk factors, $n(\%)$} \\
\hline Transient risk factor & $44(31.2)$ & $5(26.3)$ & $39(32.0)$ & 0.621 \\
\hline Prior VTE & $25(17.7)$ & $2(10.5)$ & $23(18.9)$ & 0.527 \\
\hline \multicolumn{5}{|l|}{ Laboratory data } \\
\hline \multicolumn{5}{|l|}{ eGFR continuous, median (IQR) } \\
\hline \multicolumn{5}{|l|}{ Renal dysfunction, $n$ (\%) } \\
\hline None & $102(72.3)$ & $8(42.1)$ & $94(77.0)$ & $0.002 *$ \\
\hline Transient & $17(12.1)$ & $3(15.8)$ & $14(11.5)$ & \\
\hline Maintained & $22(15.6)$ & $8(42.1)$ & $14(11.5)$ & \\
\hline D-dimer, mg/L, median (IQR) & $8.7(4.2-16.0)$ & $15.3(7.9-33.8)$ & $8.3(4.1-15.6)$ & $0.009^{*}$ \\
\hline Troponin-I (abnormal), $n(\%)$ & $20(15.3)$ & $5(26.3)$ & $15(13.4)$ & 0.169 \\
\hline $\mathrm{BNP}, \mathrm{ng} / \mathrm{L}$, median (IQR) & $319(91-922)$ & $681(196-1,006)$ & $272(76-901)$ & 0.183 \\
\hline Total cholesterol, mmol/L, median (IQR) & $4.2(3.4-5.1)$ & $3.7(3.4-4.8)$ & $4.3(3.4-5.1)$ & 0.301 \\
\hline $\mathrm{HDL}, \mathrm{mmol} / \mathrm{L}$, median $(\mathrm{IQR})$ & $0.99(0.78-1.27)$ & $0.83(0.55-0.97)$ & $1.01(0.81-1.30)$ & $0.019^{*}$ \\
\hline LDL, mmol/L, median (IQR) & $2.44(1.87-3.18)$ & $2.31(1.73-2.95)$ & $2.50(1.89-3.21)$ & 0.488 \\
\hline $\mathrm{TG}, \mathrm{mmol} / \mathrm{L}$, median (IQR) & $1.3(1.0-1.7)$ & $1.4(1.0-1.7)$ & $1.3(1.0-1.7)$ & 0.653 \\
\hline Leukocytes, $10^{9} / \mathrm{L}$, median (IQR) & $10.1(7.9-12.1)$ & $11.1(7.3-13.9)$ & $10.0(7.9-12.1)$ & 0.429 \\
\hline Hemoglobin, g/dL, median (IQR) & $13.0(11.9-14.6)$ & $12.4(11.8-15.1)$ & $13.1(11.9-14.5)$ & 0.623 \\
\hline Platelets, $10^{9} / \mathrm{L}$, median (IQR) & $224(171-296)$ & $199(145-276)$ & $227(174-298)$ & 0.149 \\
\hline
\end{tabular}

BMI, body-mass index; IQR, interquartile range; PESI, pulmonary embolism severity index; VTE, venous thromboembolism; $\mathrm{CrCl}$, creatinine clearance; eGFR, estimated glomerular filtration rate; BNP, brain natriuretic peptide; MDRD, Modification of Diet in Renal Disease; CKD-EPI, Chronic Kidney Disease Epidemiology Collaboration; HDL, high-density lipoprotein; LDL, low-density lipoprotein; TG, triglycerides. ${ }^{*} p<0.05$. 
Table 2. Patient characteristics according to mortality within 1 year

\begin{tabular}{|c|c|c|c|c|}
\hline & All patients & $\begin{array}{l}\text { 1-year } \\
\text { nonsurvivors }\end{array}$ & $\begin{array}{l}\text { 1-year } \\
\text { survivors }\end{array}$ & $p$ value \\
\hline Patients, $n(\%)$ & $141(100.0)$ & $25(17.7)$ & $116(82.3)$ & \\
\hline \multicolumn{5}{|l|}{ Demographic features } \\
\hline Age, years, mean $\pm S D$ & $66 \pm 16$ & $73 \pm 13$ & $64 \pm 16$ & $0.010^{*}$ \\
\hline Gender, female, $n(\%)$ & $87(61.7)$ & $13(52.0)$ & $74(63.8)$ & 0.271 \\
\hline \multicolumn{5}{|l|}{ Comorbidities, $n(\%)$} \\
\hline Chronic heart failure & $62(44.0)$ & $11(44.0)$ & $51(44.0)$ & 0.997 \\
\hline Chronic lung disease & $17(12.1)$ & $2(8.0)$ & $15(12.9)$ & 0.737 \\
\hline Diabetes & $22(15.6)$ & $7(28.0)$ & $15(12.9)$ & 0.072 \\
\hline Atrial fibrillation & $28(19.9)$ & $6(24.0)$ & $22(19.0)$ & 0.585 \\
\hline Myocardial infarction & $26(18.4)$ & $5(20.0)$ & $21(18.1)$ & 0.782 \\
\hline \multicolumn{5}{|l|}{ Haemodynamic data, median (IQR) } \\
\hline Systolic blood pressure, $\mathrm{mm} \mathrm{Hg}$ & $130(110-140)$ & $130(116-149)$ & $130(110-140)$ & 0.445 \\
\hline Respiratory rate, $\times / \mathrm{min}$ & $18(16-22)$ & $18(16-22)$ & $18(16-22)$ & 0.737 \\
\hline Heart rate, bpm & $90(78-104)$ & $86(73-106)$ & $90(78-104)$ & 0.332 \\
\hline \multicolumn{5}{|l|}{ Scales } \\
\hline PESI, median (IQR) & $89(74-107)$ & $111(93-138)$ & $87(70-99)$ & $<0.001^{*}$ \\
\hline \multicolumn{5}{|l|}{ Risk factors, $n(\%)$} \\
\hline Transient risk factors & $44(31.2)$ & $6(24.0)$ & $38(32.8)$ & 0.391 \\
\hline Prior VTE & $25(17.7)$ & $4(16.0)$ & $21(18.1)$ & 1.000 \\
\hline \multicolumn{5}{|l|}{ Laboratory data } \\
\hline \multicolumn{5}{|l|}{ eGFR continuous, median (IQR) } \\
\hline \multicolumn{5}{|l|}{ Renal dysfunction, $n(\%)$} \\
\hline None & $102(72.3)$ & $12(48.0)$ & $90(77.6)$ & $0.004^{*}$ \\
\hline Transient & $17(12.1)$ & $4(16.0)$ & $13(11.2)$ & \\
\hline Maintained & $22(15.6)$ & $9(36.0)$ & $13(11.2)$ & \\
\hline D-dimer, mg/L, median (IQR) & $8.7(4.2-16.0)$ & $13.5(6.5-25.4)$ & $8.3(4.1-15.6)$ & $0.033^{*}$ \\
\hline Troponin-I (abnormal), $n$ (\%) & $20(15.3)$ & $5(20.0)$ & $15(14.2)$ & 0.536 \\
\hline BNP, ng/L, median (IQR) & $319(91-922)$ & $545(142-1,016)$ & $314(78-897)$ & 0.342 \\
\hline Total cholesterol, mmol/L, median (IQR) & $4.2(3.4-5.1)$ & $3.7(3.4-4.6)$ & $4.4(3.5-5.1)$ & 0.097 \\
\hline HDL, mmol/L, median (IQR) & $0.99(0.78-1.27)$ & $0.86(0.62-1.18)$ & $1.01(0.81-1.35)$ & $0.039^{*}$ \\
\hline LDL, mmol/L, median (IQR) & $2.4(1.9-3.2)$ & $2.3(1.5-2.8)$ & $2.6(1.9-3.2)$ & 0.157 \\
\hline $\mathrm{TG}, \mathrm{mmol} / \mathrm{L}$, median (IQR) & $1.3(1.0-1.7)$ & $1.4(1.0-1.7)$ & $1.3(1.0-1.7)$ & 0.661 \\
\hline Leukocytes, $10^{9} / \mathrm{L}$, median (IQR) & $10.1(7.9-12.1)$ & $10.0(7.7-11.8)$ & $10.2(7.8-12.3)$ & 0.893 \\
\hline Hemoglobin, g/dL, median (IQR) & $13.0(11.9-14.6)$ & $12.2(11.0-14.4)$ & $13.1(12.0-14.6)$ & 0.183 \\
\hline Platelets, $10^{9} / \mathrm{L}$, median (IQR) & $224(171-295)$ & $199(152-270)$ & $227(177-301)$ & 0.110 \\
\hline
\end{tabular}


Table 3. Cox regression analysis of factors associated with mortality

\begin{tabular}{|c|c|c|c|c|}
\hline Variable & HR (95\% CI) & $p$ value & HR (95\% CI) & $p$ value \\
\hline Age (years) & $1.041(0.957-1.133)$ & 0.344 & $1.026(0.959-1.098)$ & 0.457 \\
\hline $\mathrm{BMI}\left(\mathrm{kg} / \mathrm{m}^{2}\right)$ & $1.053(0.914-1.213)$ & 0.475 & $0.980(0.861-1.116)$ & 0.765 \\
\hline Active cancer (yes) & $85.584(9.375-781.281)$ & $<0.001^{*}$ & $45.807(7.772-270.000)$ & $<0.001^{*}$ \\
\hline $\mathrm{HDL}(\mathrm{mmol} / \mathrm{L})$ & $0.188(0.021-1.659)$ & 0.132 & $0.384(0.069-2.148)$ & 0.276 \\
\hline PESI & $0.942(0.892-0.994)$ & $0.029^{*}$ & $0.965(0.924-1.008)$ & 0.108 \\
\hline \multicolumn{5}{|l|}{ Including eGFR by MDRD } \\
\hline Age (years) & $1.097(1.002-1.201)$ & $0.046^{*}$ & $1.056(0.989-1.128)$ & 0.104 \\
\hline $\operatorname{BMI}\left(\mathrm{kg} / \mathrm{m}^{2}\right)$ & $0.938(0.824-1.069)$ & 0.338 & $0.903(0.801-1.019)$ & 0.099 \\
\hline PESI & $0.940(0.887-0.995)$ & $0.034^{*}$ & $0.971(0.929-1.014)$ & 0.184 \\
\hline \multicolumn{5}{|l|}{ Including eGFR by CKD-EPI } \\
\hline Age (years) & $1.088(0.994-1.192)$ & 0.068 & $1.052(0.984-1.125)$ & 0.139 \\
\hline $\operatorname{BMI}\left(\mathrm{kg} / \mathrm{m}^{2}\right)$ & $0.943(0.827-1.075)$ & 0.380 & $0.909(0.805-1.025)$ & 0.119 \\
\hline Active cancer (yes) & $92.361(8.111-1,051.775)$ & $<0.001^{*}$ & $38.757(6.158-243.948)$ & $<0.001^{*}$ \\
\hline eGFR (CKD-EPI, $\mathrm{mL} / \mathrm{min} / \mathrm{m}^{2}$ ) & $0.948(0.915-0.983)$ & $0.003^{*}$ & $0.971(0.945-0.998)$ & $0.038^{*}$ \\
\hline D-dimer (mg/L) & $1.046(1.010-1.084)$ & $0.012^{*}$ & $1.025(0.994-1.057)$ & 0.113 \\
\hline $\mathrm{HDL}(\mathrm{mmol} / \mathrm{L})$ & $0.213(0.023-1.937)$ & 0.170 & $0.399(0.069-2.297)$ & 0.304 \\
\hline PESI & $0.937(0.884-0.994)$ & $0.031^{*}$ & $0.965(0.923-1.010)$ & 0.128 \\
\hline
\end{tabular}

BMI, body mass index; HR, hazard ratio; eGFR, estimated glomerular filtration rate; HDL, high-density lipoprotein; CKD-EPI, Chronic Kidney Disease Epidemiology Collaboration. ${ }^{*} p<0.05$.

Overall, $12.1 \%(n=17)$ of patients had transient renal dysfunction, and $15.6 \%(n=22)$ had maintained renal dysfunction. In patients with maintained renal dysfunction, 90-day and 1-year mortality was 36.4\% $(n=8)$ and $40.9 \%(n=9)$, in transient dysfunction $17.6 \%(n=3)$ and $23.5 \%(n=4)$, and in patients with no renal dysfunction $7.8 \%(n=8)$ and $11.8 \%(n=12)$. The difference between mortality rates in patients with transient, maintained, or no renal dysfunction was statistically significant $(p=$ 0.002 at 90 days; $p=0.004$ at 1 year). Differences in mortality rates between transient versus no renal dysfunction did not demonstrate statistical significance (90-day: $p=$ 0.192; 1-year: $p=0.243$ ), but significance was found between maintained versus no renal dysfunction (90-day: $p=0.001$; 1-year: $p=0.003$ ).

In univariate analyses, characteristics that were statistically significantly associated with 90-day mortality were age, presence of active cancer, higher PESI score, absolute $\mathrm{CrCl}$ value by Cockcroft-Gault, and eGFR by MDRD and CKD-EPI, as well as $\mathrm{CrCl}<60 \mathrm{~mL} / \mathrm{min}$ and eGFR $<60$ $\mathrm{mL} / \mathrm{min} / 1.73 \mathrm{~m}^{2}$, D-dimer value, and HDL level. Values that were statistically significantly associated with 1-year mortality were age, body mass index, presence of active cancer, PESI score, absolute $\mathrm{CrCl}$ value by CockcroftGault and eGFR by CKD-EPI, $\mathrm{CrCl}<60 \mathrm{~mL} / \mathrm{min}$ by Cockcroft-Gault and eGFR $<60 \mathrm{~mL} / \mathrm{min} / 1.73 \mathrm{~m}^{2}$ by MDRD and CKD-EPI, D-dimer value, and HDL level. None of the assessed hemodynamic values, comorbidities apart from cancer, and transient risk factors were associated with mortality at both 90 days and 1 year.

Variables significantly associated with mortality $(p<$ 0.05 ) in the univariate analyses were included in multivariate Cox regression model (Table 3 ). All variables were tested for collinearity using variance inflation factor in 


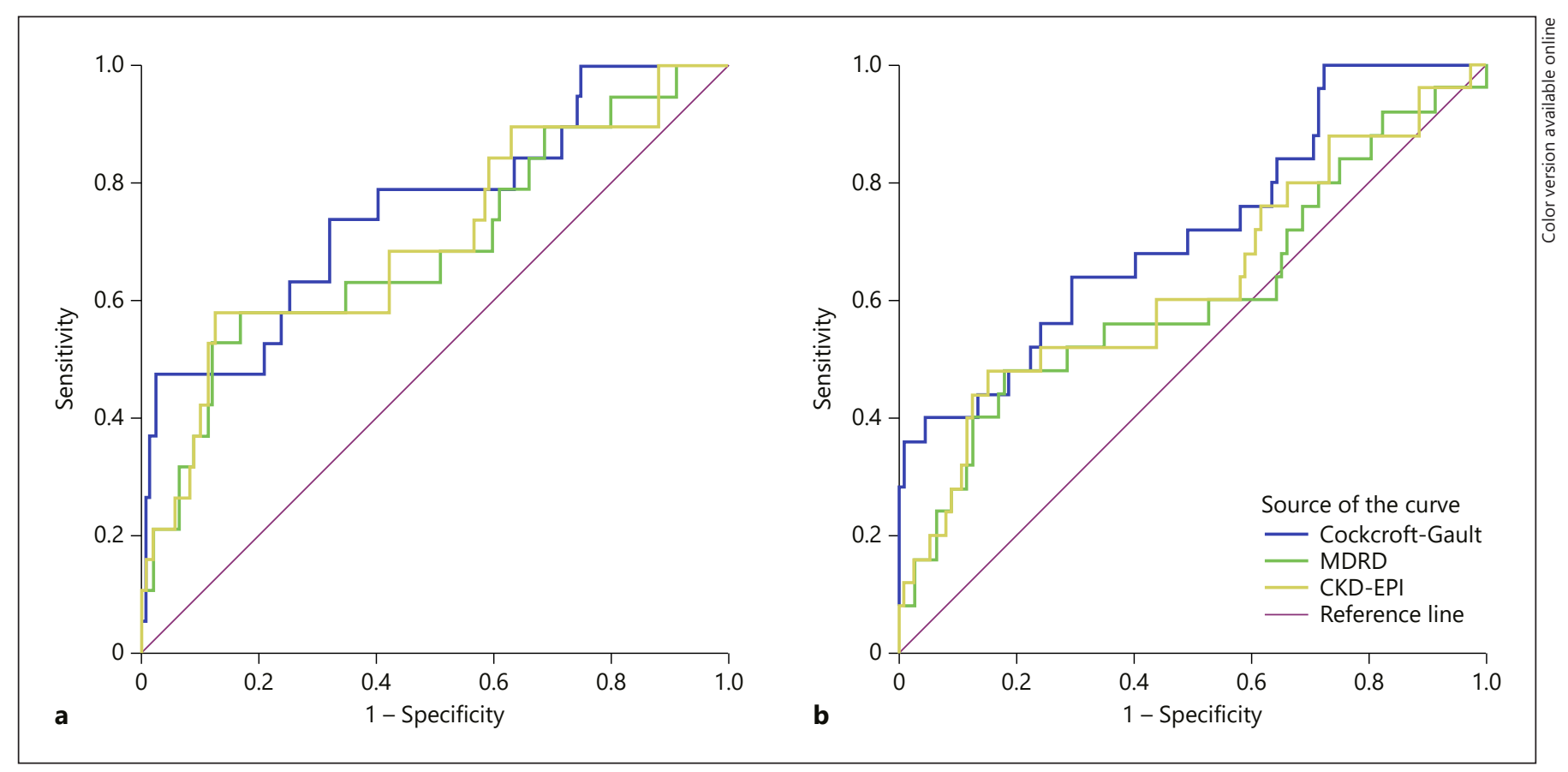

Fig. 1. ROCs for eGFR/CrCl. a 90-day follow-up. b 1-year follow-up. AUC, area under the curve; MDRD, Modification of Diet in Renal Disease; CKD-EPI, Chronic Kidney Disease Epidemiology Collaboration.

linear regression model. Value of variance inflation factor for all covariates was below 3. Proportionality assumption was tested using Cox regression time-dependent variable method - proportionality assumption was not violated for any of the covariates. $\mathrm{CrCl}$ by CockcroftGault formula demonstrated higher discriminatory power to predict mortality estimated by ROC curves than eGFR by MDRD and CKD-EPI. Log rank test was used to assess statistical significance. $\mathrm{ROC}$ curves for $\mathrm{CrCl}$ and eGFR are shown in Figure 1 and Table 4.

Using the Cox regression model, we found active cancer, $\mathrm{CrCl}$ by Cockcroft-Gault, D-dimer value, and PESI value to be independent predictors of mortality within 90 days. Active cancer and $\mathrm{CrCl}$ were also found to be significant predictors in 1-year analysis. Using $\mathrm{CrCl}$ as a categorical variable $(<60 \mathrm{~mL} / \mathrm{min})$ in the Cox regression model, hazard ratio (HR) was 21.766 (95\% CI 2.961$159.989, p=0.002$ ) for 90-day mortality, and HR 8.193 (95\% CI 1.928-34.816, $p=0.004)$ for 1-year mortality.

Although the MDRD and CKD-EPI equations demonstrated lower discriminatory power in ROC curves in comparison with Cockcroft-Gault formula, Cox regression analysis was also separately performed with eGFR calculated using MDRD and CKD-EPI equations, respectively. eGFR by MDRD as a continuous variable remained significant at 90 days but failed to demonstrate significance at 1 year. eGFR by CKD-EPI was statistically significant both at 90 days and 1 year.

\section{Discussion}

The results of our study demonstrate decreased renal function, determined by estimated $\mathrm{CrCl}$ and eGFR, as an independent statistically significant prognostic factor for increased mortality after acute PE within 90 days and 1 year. Not surprisingly, active cancer was the major predictor of death after acute PE during the follow-up period, which is consistent with earlier studies $[17,18]$; however, $\mathrm{CrCl}$ and eGFR retained significance when cancer was considered in multivariate analysis. Patients with $\mathrm{CrCl}<60 \mathrm{~mL} / \mathrm{min}$ had up to 21 -fold and 8 -fold elevated risk of death during the 90-day and 1-year follow-up period, respectively. Importantly, numerous previous studies have shown association of decreased eGFR with the occurrence or recurrence of VTE $[9,19]$. Also, previous studies have demonstrated that advanced CKD may worsen outcomes of patients presenting with acute PE, and in combination with other comorbidities may expose these patients to increased risk of mortality [10]. Mon- 
Table 4. AUC values of ROCs for eGFR/CrCl

\begin{tabular}{|c|c|c|c|c|}
\hline \multirow[t]{2}{*}{ Variable } & \multicolumn{2}{|l|}{ 90-day follow-up } & \multicolumn{2}{|l|}{ 1-year follow-up } \\
\hline & AUC (95\% CI) & $p$ value & AUC (95\% CI) & $p$ value \\
\hline CrCl by Cockcroft-Gault & $0.763(0.634-0.891)$ & $<0.001$ & $0.718(0.601-0.835)$ & 0.001 \\
\hline eGFR by MDRD & $0.686(0.541-0.830)$ & 0.010 & $0.609(0.472-0.746)$ & 0.090 \\
\hline eGFR by CKD-EPI & $0.697(0.554-0.839)$ & 0.006 & $0.630(0.497-0.763)$ & 0.043 \\
\hline
\end{tabular}

$\mathrm{CrCl}$, creatinine clearance; eGFR, estimated glomerular filtration rate; AUC, area under the curve; MDRD, Modification of Diet in Renal Disease; CKD-EPI, Chronic Kidney Disease Epidemiology Collaboration.

real et al. [11] show that the ORs for fatal PE in patients with $\mathrm{CrCl}$ between 30 and $60 \mathrm{~mL} / \mathrm{min}$ and in those with $\mathrm{CrCl}<30 \mathrm{~mL} / \mathrm{min}$ are 2.7 and 7.2 , respectively, compared to subjects in whom $\mathrm{CrCl}$ was $>60 \mathrm{~mL} / \mathrm{min}$. Kidney dysfunction has been previously observed in patients with acute $\mathrm{PE}$ and was found to be associated with worse shortterm outcomes [12-14]. GFR was lower in nonsurvivors than in survivors ( 35 vs. $63 \mathrm{~mL} / \mathrm{min}, p<0.0001$ ) in a prospective cohort study performed in Poland with AUC values similar to our study [13]. These studies, however, have only assessed short-term outcomes of acute PE.

Regarding long-term data, lower eGFR has been demonstrated as an independent predictor of 2-year mortality (OR $0.973, p<0.001)$ with mortality rate of $20 \%$ in patients with moderate renal dysfunction associated with right ventricular dysfunction [20]. The HRs for 90-day and 1-year mortality in our study are comparable to these results. A population-based cohort study in Canada also demonstrated that the adjusted HR for death increased with higher albumin-creatinine ratio and lower eGFR category [21]. In several studies of PE outcomes, eGFR has been assessed using a single creatinine measurement $[13,19-21]$; however, patients with acute PE may experience a transient decline of renal function, which improves during treatment. We attempted to group patients according to either transient or maintained nature of the decline of their renal function. Patients with maintained, that is, chronic dysfunction had statistically significantly higher mortality rates at both 90 days and 1 year than patients with normal renal function, whereas transient dysfunction did not significantly demonstrate such an association.

Median D-dimer value was an independently significant prognostic factor in 90-day follow-up in Cox regression; however, it failed to retain significance in 1-year analysis. Several studies have shown an association between elevated D-dimer and increased mortality in 30 days and 3 months after PE. Similarly, it has been associated with higher mortality in cancer patients [22]. PESI was determined to be an independent prognostic factor in the 90-day follow-up period but not at 1-year followup. Although PESI was designed as a tool for predicting the 30-day mortality rate, it has been shown to perform accurately also in 3, 6, and 12 months [23]. Unlike what has been reported by numerous authors [20, 24-26], no other routine laboratory tests, including abnormal troponin-I and BNP, or other comorbidities were independent predictors of death in our study. These inconsistencies may be caused by technical limitations of our study due to its observational, noninterventional nature. For instance, BNP levels were tested only in about one-half of patients at nonstandardized points in time. Troponin-I was registered only as normal or abnormal with specific values available only for abnormal values; hence, the abilities of statistical analysis were limited.

\section{Limitations}

A limitation of our study is the relatively low patient sample size. Due to the modest sample size and lack of uniformly precise documentation of the etiology of death, the causes were not further separated, and only all-cause mortality was assessed. Another potential source of bias was the fact that only patients with PE objectively confirmed by CTPA were included in this study; we left out a considerable number of patients with clinically high suspicion PE whose renal function precluded the use of contrast medium to objectively confirm the diagnosis. Ventilation/perfusion scintigraphy is not performed routinely in our hospital. Many patients with impaired renal function upon admission did not have any previous records of CKD even if their creatinine levels remained elevated during their hospital stay. Six patients (35\%) who were included in the transient renal dysfunction category did not have repeated measurements; however, none of 
them had any medical records of CKD, and their reduction in renal function was generally mild. Because of the observational nature of this study, no subsequent standardized follow-up blood chemistry data were recorded, hence, in some cases, acute and chronic renal dysfunction could not be reliably differentiated.

However, as most studies have focused on renal dysfunction in association with increased short-term mortality only, the benefit of our study is that it shows the effect of decreased baseline $\mathrm{CrCl}$ and eGFR on mortality in the 90 -day and 1-year perspective. This study further confirms and elucidates the importance of renal function not only as a short-term but also a long-term prognostic marker for patients with acute PE. Further research is warranted to assess the usefulness of $\mathrm{CrCl}$ and eGFR as a tool for risk stratification.

\section{Conclusion}

In our patient cohort, decreased $\mathrm{CrCl}$ or eGFR was shown to be an independent prognostic factor for increased allcause mortality in 90 days and 1 year after acute PE. Maintained reduction of renal function was significantly associated with higher mortality. D-dimer had prognostic value only in 90-day follow-up period. There was no significant value of comorbidities apart from cancer to predict longterm mortality after PE. We should be aware of the fact that not only are reduced $\mathrm{CrCl}$ and eGFR associated with higher risk for $\mathrm{PE}$ but $\mathrm{CrCl}$ and eGFR also predict short- and longterm mortality after the episode of PE. Future studies are required for the development of strategies to prevent afterVTE events in case of decreased $\mathrm{CrCl}$ and eGFR.

\section{Disclosure Statement}

The authors state that they have no conflicts of interest.

\section{References}

1 DeMonaco NA, Dang Q, Kapoor WN, Ragni MV. Pulmonary embolism incidence is increasing with use of spiral computed tomography. Am J Med. 2008 Jul;121(7):611-7.

2 Burge AJ, Freeman KD, Klapper PJ, Haramati LB. Increased diagnosis of pulmonary embolism without a corresponding decline in mortality during the CT era. Clin Radiol. 2008 Apr;63(4):381-6.

3 Heit JA, Spencer FA, White RH. The epidemiology of venous thromboembolism. J Thromb Thrombolysis. 2016 Jan;41(1):3-14.

4 Hillege HL, Nitsch D, Pfeffer MA, Swedberg K, McMurray JJ, Yusuf S, et al.; Candesartan in Heart Failure: Assessment of Reduction in Mortality and Morbidity (CHARM) Investigators. Renal function as a predictor of outcome in a broad spectrum of patients with heart failure. Circulation. 2006 Feb;113(5): 671-8.

5 Mahmoodi BK, ten Kate MK, Waanders F, Veeger NJ, Brouwer JL, Vogt L, et al. High absolute risks and predictors of venous and arterial thromboembolic events in patients with nephrotic syndrome: results from a large retrospective cohort study. Circulation. 2008 Jan;117(2):224-30.

6 Stein PD, Henry JW. Prevalence of acute pulmonary embolism among patients in a general hospital and at autopsy. Chest. 1995 Oct; 108(4):978-81.

7 Kayali F, Najjar R, Aswad F, Matta F, Stein PD. Venous thromboembolism in patients hospitalized with nephrotic syndrome. Am J Med. 2008 Mar;121(3):226-30.
8 Wattanakit K, Cushman M, Stehman-Breen C, Heckbert SR, Folsom AR. Chronic kidney disease increases risk for venous thromboembolism. J Am Soc Nephrol. 2008 Jan;19(1):135-40.

9 Mahmoodi BK, Gansevoort RT, Næss IA, Lutsey PL, Brækkan SK, Veeger NJ, et al. Association of mild to moderate chronic kidney disease with venous thromboembolism: pooled analysis of five prospective general population cohorts. Circulation. 2012 Oct;126(16):1964-71.

10 Fabbian F, Gallerani M, Pala M, De Giorgi A, Salmi R, Manfredini F, et al. In-hospital mortality for pulmonary embolism: relationship with chronic kidney disease and end-stage renal disease. The hospital admission and discharge database of the Emilia Romagna region of Italy. Intern Emerg Med. 2013 Dec;8(8):735-40.

11 Monreal M, Falgá C, Valle R, Barba R, Bosco J, Beato JL, et al.; RIETE Investigators. Venous thromboembolism in patients with renal insufficiency: findings from the RIETE Registry. Am J Med. 2006 Dec;119(12):1073-9.

12 Kumar G, Sakhuja A, Taneja A, Majumdar T, Patel J, Whittle J, et al.; Milwaukee Initiative in Critical Care Outcomes Research (MICCOR) Group of Investigators. Pulmonary embolism in patients with CKD and ESRD. Clin J Am Soc Nephrol. 2012 Oct;7(10):1584-90.

13 Kostrubiec M, Łabyk A, Pedowska-Włoszek J, Pacho S, Wojciechowski A, Jankowski K, et al. Assessment of renal dysfunction improves troponin-based short-term prognosis in patients with acute symptomatic pulmonary embolism. J Thromb Haemost. 2010 Apr; $8(4): 651-8$
14 Berghaus TM, Behr W, von Scheidt W, Schwaiblmair M. The N-terminal pro-braintype natriuretic peptide based short-term prognosis in patients with acute pulmonary embolism according to renal function. J Thromb Thrombolysis. 2012 Jan;33(1):58-63.

15 Heit JA, Silverstein MD, Mohr DN, Petterson TM, O'Fallon WM, Melton LJ 3rd. Predictors of survival after deep vein thrombosis and pulmonary embolism: a population-based, cohort study. Arch Intern Med. 1999 Mar;159(5):445-53.

16 Kostrubiec M, Łabyk A, Pedowska-Włoszek J, Dzikowska-Diduch O, Wojciechowski A, Garlińska M, et al. Neutrophil gelatinase-associated lipocalin, cystatin C and eGFR indicate acute kidney injury and predict prognosis of patients with acute pulmonary embolism. Heart. 2012 Aug:98(16):1221-8.

17 Klok FA, Zondag W, van Kralingen KW, van Dijk AP, Tamsma JT, Heyning FH, et al. Patient outcomes after acute pulmonary embolism. A pooled survival analysis of different adverse events. Am J Respir Crit Care Med. 2010 Mar; 181(5):501-6.

18 Spencer FA, Goldberg RJ, Lessard D, Reed G, Emery C, Gore JM, et al. Factors Associated with Adverse Outcomes in Outpatients Presenting with Pulmonary Embolism: the Worcester VTE Study. Circ Cardiovasc Qual Outcomes. 2010;3(4):390-4.

19 Rattazzi M, Villalta S, De Lucchi L, Sponchiado A, Galliazzo S, Faggin E, et al. Chronic kidney disease is associated with increased risk of venous thromboembolism recurrence. Thromb Res. 2017 Dec;160:32-7. 
20 Ouatu A, Tãnase DM, Floria M, Ionescu SD, Ambãruș V, Arsenescu-Georgescu C. Chronic kidney disease: prognostic marker of nonfatal pulmonary thromboembolism. Anatol J Cardiol. 2015 Nov;15(11):938-43.

21 Massicotte-Azarniouch D, Bader Eddeen A, Lazo-Langner A, Molnar AO, Lam NN, McCallum MK, et al. Risk of Venous Thromboembolism in Patients by Albuminuria and Estimated GFR. Am J Kidney Dis. 2017 Dec; 70(6):826-33.

22 Halaby R, Popma CJ, Cohen A, Chi G, Zacarkim MR, Romero G, et al. D-Dimer elevation and adverse outcomes. J Thromb Thrombolysis. 2015 Jan;39(1):55-9.
23 Dentali F, Riva N, Turato S, Grazioli S, Squizzato A, Steidl L, et al. Pulmonary embolism severity index accurately predicts long-term mortality rate in patients hospitalized for acute pulmonary embolism. J Thromb Haemost. 2013 Dec;11(12):2103-10.

24 Verschuren F, Bonnet M, Benoit MO, Gruson D, Zech F, Couturaud F, et al. The prognostic value of pro-B-Type natriuretic peptide in acute pulmonary embolism. Thromb Res. 2013 Jun;131(6):e235-9.
$25 \mathrm{Ng}$ AC, Yong AS, Chow V, Chung T, Freedman SB, Kritharides L. Cardiac troponin-T and the prediction of acute and long-term mortality after acute pulmonary embolism. Int J Cardiol. 2013 Apr;165(1):126-33.

26 Konstantinides S, Geibel A, Olschewski M, Kasper W, Hruska N, Jäckle S, et al. Importance of cardiac troponins I and $\mathrm{T}$ in risk stratification of patients with acute pulmonary embolism. Circulation. 2002 Sep; 106(10):1263-8. 